\title{
Somewhat saved: a captive breeding programme for two endemic Christmas Island lizard species, now extinct in the wild
}

\author{
Paul Andrew, Hal Cogger, Don Driscoll, Samantha Flakus, Peter Harlow \\ Dion Maple, Mike Misso, Caithin Pink, Kent Retallick, Karrie Rose \\ BRENDAN TiERnAN, Judy West and John C.Z. Woinarski
}

\begin{abstract}
As with many islands, Christmas Island in the Indian Ocean has suffered severe biodiversity loss. Its terrestrial lizard fauna comprised five native species, of which four were endemic. These were abundant until at least the late 1970s, but four species declined rapidly thereafter and were last reported in the wild between 2009 and 2013. In response to the decline, a captive breeding programme was established in August 2009. This attempt came too late for the Christmas Island forest skink Emoia nativitatis, whose last known individual died in captivity in 2014, and for the non-endemic coastal skink Emoia atrocostata. However, two captive populations are now established for Lister's gecko Lepidodactylus listeri and the blue-tailed skink Cryptoblepharus egeriae. The conservation future for these two species is challenging: reintroduction will not be possible until the main threats are identified and controlled.
\end{abstract}

Keywords Christmas Island, extinction, gecko, Indian Ocean, reintroduction, skink

T slands provide many of the world's most important con1 servation opportunities and challenges. Many have a high complement of endemic species but these often have small populations, limited genetic diversity and low reproductive rates, lack immunity to novel diseases or are predator-naive. These characteristics mean that island species have little resilience to introduced predators, consumers, competitors

Paul Andrew, Peter Harlow and Karrie Rose Taronga Conservation Society Australia, Bradleys Head Road, Mosman, New South Wales, Australia

Hal Cogger Australian Museum Research Institute, Sydney, New South Wales, Australia

Don DRISCOLL School of Life and Environmental Sciences, Deakin University, Burwood, Victoria, Australia

Samantha Flakus, Dion Maple, Mike Misso, Caitlin Pink, Kent Retallick and Brendan Tiernan Parks Australia, Christmas Island, Indian Ocean, Australia

Judy West Department of the Environment, Parks Australia, Canberra, Australian Capital Territory, Australia

John C. Z. WoINARsKi (Corresponding author) Threatened Species Recovery Hub, Charles Darwin University, Casuarina, Northern Territory 0909, Australia. E-mail john.woinarski@cdu.edu.au

Received 15 July 2016. Accepted 5 September 2016. First published online 30 November 2016 or diseases, or to other environmental modifications. Consequently, island species are over-represented among the world's recent extinctions (Duncan \& Blackburn, 2007).

In many cases, conservation management responses for island species have been ineffective. Often, resources have been inadequate to respond to synchronous declines of many species. On many islands there are multiple threats and it is difficult to disentangle their relative or synergistic impacts, and hence to target management responses most effectively. Furthermore, there may be limited options for in situ conservation, and many threats may be difficult to control (Fritts \& Rodda, 1998).

The Australian Indian Ocean territory of Christmas Island has high levels of endemism but many of these endemic species have declined or become extinct. For example, of five native mammal species, at least four of which were endemic, only the Christmas Island flying-fox Pteropus (melanotus) natalis, is known to be extant, and it is now Critically Endangered (Woinarski et al., 2014). Notably, the Christmas Island pipistrelle Pipistrellus murrayi was abundant up to the 1980 os but declined rapidly to extinction in 2009. The failure to conserve this species has been the subject of critical review (Martin et al., 2012).

Christmas Island is a $135 \mathrm{~km}^{2}$ island in the Indian Ocean $\left(10^{\circ} 25^{\prime} \mathrm{S}, 105^{\circ} 43^{\prime} \mathrm{E}\right), 360 \mathrm{~km}$ distant from the nearest land (Java, Indonesia). It was settled in the 188 os, for phosphate mining; $27 \%$ of the island has been cleared but it has otherwise mostly retained its original rainforest, and $63 \%$ is national park.

Many species have been introduced to Christmas Island and are now widespread even in intact native vegetation. Across much of the island super-colonies of the introduced yellow crazy ant Anoplolepis gracilipes have subverted the previous crab-mediated ecology, leading to an invasional meltdown' (O'Dowd et al., 2003). The abundance of yellow crazy ants has been periodically controlled through broadscale application of insecticides.

Introduced species known or presumed to prey upon Christmas Island lizards include the feral cat Felis catus (introduced in the 1890s), black rat Rattus rattus (1900), giant centipede Scolopendra subspinipes (190os) and wolf snake Lycodon capucinus (c. 1982). All are now common across the island. An eradication programme is being implemented for feral cats, but no broad-scale management for the other 
predators has been undertaken. Three lizard species that may be potential competitors to and disease vectors for native reptiles have been introduced: the geckoes Hemidactylus frenatus (first recorded in 1947) and Gehyra mutilata (1979) and skink Lygosoma bowringii (1979).

The reptile fauna comprised six native species: the endemic Christmas Island blind snake Ramphotyphlops exocoeti, the Christmas Island forest skink Emoia nativitatis, the bluetailed skink Cryptoblepharus egeriae, the giant gecko Cyrtodactylus sadleiri and Lister's gecko Lepidodactylus listeri, and the non-endemic coastal skink Emoia atrocostata.

The blue-tailed skink (snout-vent length c. $45 \mathrm{~mm}$ ) forages actively in low vegetation or on the ground. Lister's gecko (c. $45 \mathrm{~mm}$ ) is nocturnal and arboreal. The forest skink (c. $70 \mathrm{~mm}$ ) occurred mostly in forest gap and edge habitats. The coastal skink (c. $100 \mathrm{~mm}$ ) occurred mainly in rocky littoral habitats (Cogger et al., 1983).

Although there are only six records of the blind snake since 1910 (Maple et al., 2012), the five lizards were generally common until at least 1979 (Cogger et al., 1983). Declines of the blue-tailed skink were first reported in 1992 (Rumpff, 1992) and of the forest skink, coastal skink and Lister's gecko in 1998 (Cogger \& Sadlier, 1999), with ongoing declines reported between 2004 and 2008 (James, 2004; Schulz \& Barker, 2008). For reasons not yet understood, the giant gecko remains abundant and widespread.

In response to the decline of four lizard species, a captive breeding programme was initiated in 2009. Here we describe the progress and outlook of this programme. The role and cost-effectiveness of captive breeding within a broader conservation context has been a focus of considerable global interest (Bowkett, 2009). In this case, it was justified by the rapid declines (Smith et al., 2012) and the likelihood that threats could not be controlled in the wild in the short time period before the probable extinction of these species. Despite a series of intensive and extensive searches, the last records of the Christmas Island population of coastal skink were in September 2009, of the forest skink and blue-tailed skink in August 2010, and of Lister's gecko in October 2012.

From August 2009 as many individuals as possible of the four declining species were collected from the wild. Three forest skinks (all females), 43 Lister's geckoes and 64 bluetailed skinks were captured and housed in purpose-built facilities. No coastal skinks and no male forest skinks could be captured. The last of the three forest skinks died on 31 May 2014, the presumed extinction date for this species. The coastal skink still occurs beyond Christmas Island.

To reduce the risk of catastrophic loss, separate on- and off-island (at Taronga Zoo in Sydney, c. $5000 \mathrm{~km}$ distant) captive populations were established for both the blue-tailed skink and Lister's gecko. From the wild-caught population and its F1 descendants, 56 Lister's geckoes and 83 blue-tailed skinks were transferred to Taronga in three batches in May, June and November 2011; the remaining 70 captive Lister's

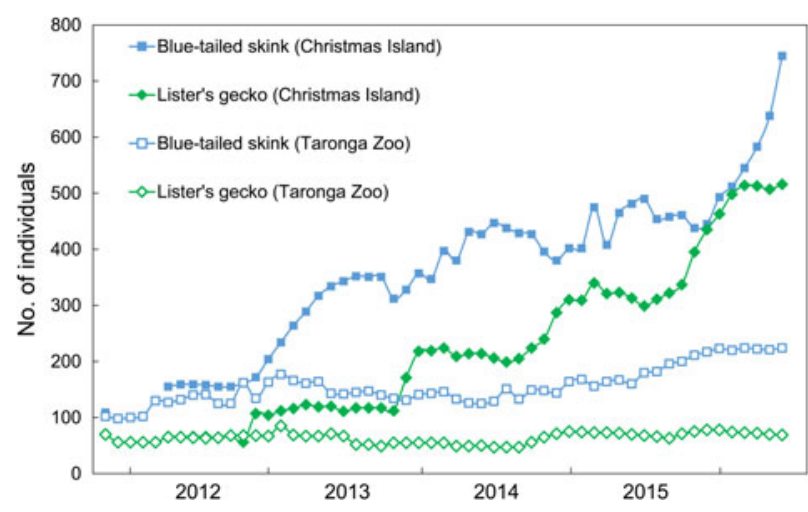

FIG. 1 Changes in the size of captive-breeding populations of blue-tailed skink Cryptoblepharus egeriae and Lister's gecko Lepidodactylus listeri from November 2011 to May 2016 on Christmas Island and at Taronga Zoo.

geckoes and 109 blue-tailed skinks (at November 2011) were maintained at facilities on Christmas Island.

These have been treated as independent units (i.e. without interchange of individuals after establishment). Management by Mean Kinship (Ballou \& Lacy, 1995) was used to maximize retention of genetic diversity for Lister's gecko at Taronga, and management by Maximal Avoidance of Inbreeding (Princée, 1995) was used for blue-tailed skinks at both sites, and for Lister's gecko at Christmas Island. Detailed husbandry information is not presented here.

Captive populations have been monitored since November 2011; they have been stable at Taronga, and have increased on Christmas Island (Fig. 1). These results provide evidence of some success, but what are the local and broader contexts of this programme, and how can this limited success be consolidated?

Reptiles are currently undergoing a severe global decline, with increasing numbers of threatened species and extinctions (Gibbons et al., 2000). Loss is particularly pronounced for species with small ranges, especially island species. Increasingly, captive breeding and translocation are likely to be necessary mechanisms to forestall extinctions for the most threatened species. The Christmas Island lizards present a sobering example. The five species were abundant and presumed secure in 1979 (and perhaps remained so for at least another decade), having withstood nearly 100 years of human settlement and many introductions. But by 2012 four of these species had disappeared from the wild. The conservation response to this decline was mixed. Because of limited monitoring, the decline was not detected until 1992 (localized; Rumpff, 1992) or 1998 (more widely; Cogger \& Sadlier, 1999), and its extreme extent was not recognized until c. 2005 (James, 2004; Schulz \& Barker, 2008). Managers took several years to respond, partly because there was some hope that the reptiles would benefit from extensive control then being implemented for what was perceived to be the main threat to the island's ecology, the yellow crazy 
ant (Green \& O’Dowd, 2009). Delay was also a result of the absence of bureaucratic levers: the pace of decline outstripped formal assessment and listing of these species as threatened. The forest skink and blue-tailed skink were not listed as threatened under Australian legislation until January 2014, only 4 months before the forest skink's extinction. Furthermore, the pace of decline left researchers little opportunity to identify the primary cause, and hence little capacity for preventative management. When urgent action (the captive breeding programme described here) was implemented, it came too late for two species.

However, this programme has averted extinction for two species. Captive populations of blue-tailed skink and Lister's gecko are now secured, and are increasing. But this is only a holding pattern, and may be unsustainable. The current programme represents a substantial investment (c. AUD 200,000 annual expenses and c. AUD 250,000 of infrastructure funding since 2011), and perennial support for maintaining it cannot be guaranteed.

Captive breeding is a means to an end rather than an endpoint itself (IUCN/SSC, 2014). The ultimate objective of this programme is the re-establishment of viable populations in the wild. However, that pathway has formidable challenges, mostly because the primary threat(s) remain unknown and uncontrolled. Currently, we are using a small pool of surplus male blue-tailed skinks in small-scale $\left(\right.$ c. $\left.25 \mathrm{~m}^{2}\right)$ predatorexclosure trials on Christmas Island, to attempt to identify the critical threats, and assess whether these can be controlled at least locally. However, there may be no option available immediately for broader-scale control of some threats, particularly of wolf snakes and giant centipedes.

In many island conservation projects elsewhere, reestablishment has been staged through translocation to nearby small islands on which the primary threat is absent or can be controlled. This is not an option at Christmas Island, given its isolation and lack of satellite islands. With due regard to biosecurity concerns, we are currently evaluating translocation options to islets in the Cocos (Keeling) group, $860 \mathrm{~km}$ west of Christmas Island, which support no native reptile species.

\section{Acknowledgements}

We thank Parks Australia, Taronga Zoo, Foundation for National Parks and Wildlife and Chris Bray Photography safari tours for support; Mike Smith for help establishing this programme; and Jane Hall, Paul Thompson, Frances Hulst, Kimberly Vinette-Herrin, and Larry Vogelnest for help managing the Taronga populations.

\section{Author contributions}

JW provided overall direction for this programme, with independent expert advice from a panel, including PA, HC,
DD, SF, PH, DM, MM, BT and JCZW. This article was drafted by JCZW, with subsequent inputs from all coauthors. $\mathrm{PA}, \mathrm{PH}$ and $\mathrm{KR}$ established and have maintained the captive population at Taronga, and SF, DM, MM, CP, $\mathrm{KR}$ and $\mathrm{BT}$ have maintained the captive population at Christmas Island.

\section{References}

BaLLOU, J.D. \& LACY, R.C. (1995) Identifying genetically important individuals for management of genetic diversity in pedigreed populations. In Population Management for Survival and Recovery: Analytical Methods and Strategies in Small Population Conservation (eds J.D. Ballou, M. Gilpin \& T. J. Foose), pp. 76-111. Columbia University Press, New York, USA.

Bowketт, A.E. (2009) Recent captive-breeding proposals and the return of the ark concept to global species conservation. Conservation Biology, 23, 773-776.

Cogger, H.G. \& S Adlier, R. (1999) The Terrestrial Reptiles of Christmas Island: A Reappraisal of Their Status. The Australian Museum, Sydney, Australia.

Cogger, H.G., Sadlier, R. \& Cameron, E. (1983) The Terrestrial Reptiles of Australia's Island Territories. Australian National Parks and Wildlife Service, Canberra, Australia.

Duncan, R.P. \& Blackburn, T.M. (2007) Causes of extinction in island birds. Animal Conservation, 10, 149-150.

Fritts, T.H. \& Rodda, G.H. (1998) The role of introduced species in the degradation of island ecosystems: a case history of Guam. Annual Review of Ecology and Systematics, 29, 113-140.

Gibbons, J.W., Scott, D.E., Ryan, T.J., Buhlmann, K.A., Tuberville, T.D., Metts, B.S. et al. (2000) The global decline of reptiles, déjà vu amphibians. BioScience, 50, 653-666.

Green, P.T. \& O’Dowd, D.J. (2009) Management of invasive invertebrates: lessons from the management of an invasive alien ant. In Invasive Species Management: A Handbook of Principles and Techniques (eds M.N. Clout \& P.A. Williams), pp. 153-172. Oxford University Press, New York, USA.

IUCN/SSC (IUCN Species Survival Commission) (2014) Guidelines on the Use of Ex Situ Management for Species Conservation. Version 2.o. IUCN Species Survival Commission, Gland, Switzerland.

James, D.J. (2004) Christmas Island Biodiversity Monitoring Programme: Third Quarterly Report for the Period April to June 2004. Parks Australia North, Christmas Island, Australia.

Maple, D.J., Barr, R. \& SMith, M.J. (2012) A new record of the Christmas Island blind snake, Ramphotyphlops exocoeti (Reptilia: Squamata: Typhlopidae). Records of the Western Australian Museum, 27, 156-160.

Martin, T.G., Nally, S., Burbidge, A.A., Arnall, S., Garnett, S. T., Hayward, M.W. et al. (2012) Acting fast helps avoid extinction. Conservation Letters, 5, 274-280.

O’Dowd, D.J., Green, P.T. \& LaKe, P.S. (2003) Invasional 'meltdown' on an oceanic island. Ecology Letters, 6, 812-817.

Princée, F. (1995) Overcoming the constraints of social structure and incomplete pedigree data through low-intensity genetic management. In Population Management for Survival and Recovery: Analytical Methods and Strategies in Small Population Conservation (eds J.D. Ballou, M. Gilpin \& T.J. Foose), pp. 124-154. Columbia University Press, New York, USA.

RumpfF, H. (1992) Distribution, Population Structure and Ecological Behaviour of the Introduced South-East Asian Wolf Snake Lycodon 
aulicus capucinus on Christmas Island, Indian Ocean. Australian National Parks and Wildlife Service, Christmas Island, Australia.

Schulz, M. \& Barker, C. (2008) A Terrestrial Reptile Survey of Christmas Island, May-June 2008. Parks Australia North, Christmas Island, Australia.

Smith, M.J., Cogger, H., Tiernan, B., Maple, D., Boland, C., NApier, F. et al. (2012) An oceanic island reptile community under threat: the decline of reptiles on Christmas Island, Indian Ocean. Herpetological Conservation and Biology, 7, 206-218.

Woinarski, J.C.Z., Burbidge, A.A. \& Harrison, P.L. (2014) The Action Plan for Australian Mammals 2012. CSIRO Publishing, Melbourne, Australia.

\section{Biographical sketches}

Judy West is Assistant Secretary, Parks Australia, and Chair of the Christmas Island Reptile Advisory Panel. HAL Cogger, DoN Driscoll and John WoINARSKi are independent advisors to the Panel. Paul Andrew and Peter Harlow manage the populations held at TARONga Zoo. Karrie Rose is a veterinary scientist managing the Australian Registry of Wildlife Health at Taronga Conservation Society Australia. Samantha Flakus, Dion Maple, Caitlin Pink, Kent Retallick and Brendan Tiernan are with Parks Australia, and oversee the programme there. Miке Misso was formerly Manager of Christmas Island National Park. 